\title{
3D bearing capacity probabilistic analyses of footings on spatially variable $c-\varphi$ soil
}

\author{
Marek Kawa $^{1}$ (D) Wojciech Puła ${ }^{1}$
}

Received: 4 December 2018 / Accepted: 17 June 2019/Published online: 4 July 2019

(C) The Author(s) 2019

\begin{abstract}
The paper examines three-dimensional (3D) analyses of the load bearing capacity of square and strip footings on a spatially variable cohesive-frictional $(c-\varphi)$ soil. Embedded, rigid and smooth footings are considered. Cohesion and friction angle are modelled using random fields. The vertical scale of fluctuation (SOF) is based on earlier studies of natural soils. For the square footing problem, the horizontal SOF is the subject of a parametric study. For the strip footing, only one value of the horizontal SOF is assumed, and the parametric study concerns the modelled length of the foundation. To generate the fields of strength parameters, the Fourier series method is employed. For both problems analyzed, the influence of the parameters on the probabilistic characteristics of the bearing capacity of the soil is investigated. For the square footing problem, both the mean value of bearing capacity and its coefficient of variation increase with an increasing horizontal fluctuation scale, but they stabilize at higher values of SOF. For the strip footing problem, it appears that 2D modelling is a very conservative approach, and for the precise assessment of the probability of foundation failure, the footing should be modelled in $3 \mathrm{D}$.
\end{abstract}

Keywords FLAC3D $\cdot$ Random field $\cdot$ Reliability index $\cdot$ Scale of fluctuation

\section{List of symbols}

\section{Roman}

a Lower bound of bounded interval

$b \quad$ Upper bound of bounded interval

$\mathrm{CoV}$ Coefficient of variation

c Cohesion

$D \quad$ Domain

E Young's modulus

$l \quad$ Modelled length of strip foundation

$m \quad$ Parameter of the utilized bounded distribution of the hyperbolic tangent type

$N \quad$ Number of Monte Carlo simulations (sample size)

$p_{\mathrm{f}} \quad$ Probability of failure

$Q_{\mathrm{d}} \quad$ Maximum allowable value of foundation load

$Q_{\mathrm{f}} \quad$ Bearing capacity of foundation

$q_{\mathrm{c}} \quad$ Cone resistance

$s \quad$ Parameter of the utilized bounded distribution of the hyperbolic tangent type

Marek Kawa

marek.kawa@pwr.edu.pl

1 Wrocław University of Science and Technology, Wrocław, Poland

$t \quad$ Independent variable

$x, y, z \quad$ Coordinates

$\mathbf{x} \quad$ Point in a domain $D$, with coordinates $(x, y, z)$

$X(\mathbf{x}) \quad$ Normally distributed random field

$Y(\mathbf{x}) \quad$ Field transformed from normally distributed one

\section{Greek}

$\beta$

$\theta_{x}, \theta_{y}, \theta_{z}$

$\mu$

$\mu_{\ln Y}$

$v$

$\rho$

$\sigma$

$\sigma_{\ln Y}$

$\tau_{x}, \tau_{y}, \tau_{z}$

$\Phi$

$\varphi$

$\psi$
Reliability index

Scale of fluctuation (SOF) in three directions

Mean value

Mean value of normal distribution underlying log-normal one

Poisson's ratio

Correlation function

Standard deviation

Standard deviation of normal distribution underlying lognormal one

Distance between points in three directions

Cumulative distribution function of the standard normal distribution

Friction angle

Dilation angle 


\section{Introduction}

The past 20 years have seen increasingly rapid advances in the field of random analysis of foundations based on modelling spatial variability in soil properties using random fields. Many researchers have studied this problem $[1,4,9,14,16,20,29,32,36]$. The pioneering work on this subject by Griffiths and Fenton [15] and Fenton and Griffiths [12] analyzed the random bearing capacity of strip foundations. The academic problems were initially limited to embedded foundations on purely cohesive soils modelled with isotropic fields, but have recently been developed for studies that involve analyses of design situations involving foundations on frictional as well as cohesive soils. For example, in the work of Pieczyńska-Kozłowska et al. [30], the bearing capacity of an embedded strip foundation on a natural cohesive-frictional soil was analyzed.

The random analysis of such nonlinear problems requires significant computing power. This is probably the reason why papers examining the three-dimensional (3D) effects of geotechnical problems with variable soil are limited in number. One exception was the early work of Fenton and Griffiths [13] in which foundation settlement was analyzed in 3D. However, the problem in that case was linear, which strongly simplified the computation process. The plasticity problem for spatially variable soil in 3D started to be analyzed during the previous decade, and until recently [especially for a significant number of Monte Carlo simulations (MCS)], was beyond the computing capabilities of personal computers. A good example of such an analysis was the series of papers presented by Hicks et al. [17-19, 26, 27]. To analyze a sufficient number of realizations of the large-scale 3D slopes, the authors employed high-performance computing clusters.

The first probabilistic 3D analysis of a square footing on soil with strength modelled with random fields was carried out by Al-Bittar and Soubra [3] (and in the Ph.D. thesis of Al-Bittar [2]). The FLAC3D finite difference code was used to solve the boundary value problem. Because the direct use of the finite difference code was computationally demanding, a metamodel was developed based on sparse polynomial chaos expansion combined with global sensitivity analysis. Simoes et al. [35] used an upper bound formulation of finite element limit analysis (FELA) in order to check the influence of modelling strip foundations on spatially variable 3D soil with regard to the probability characteristics of structure bearing capacity. For these simulations, the Latin hypercube sampling technique was used, which allowed the limiting of a satisfactory number of simulations compared to the crude Monte Carlo technique. The computations were performed using a cluster with a total number of 102 cores. Both of the above studies concerned undrained (or purely cohesive) soil media and not embedded foundations.

The surface square footing was also analyzed in one of the earlier studies by the authors of the present paper [23]. The local average subdivision (LAS) procedure was utilized as the method for random field generation. The analysis involved both purely cohesive and cohesive-frictional soils. The boundary value problem was solved using the FLAC3D code. Since this work was a preliminary study, it was simplified by assuming that soil variability takes place in only the vertical direction. (The soil properties were assumed not to vary in the horizontal direction so that the horizontal scale of fluctuation was infinity.)

It should be noted that the task of analyzing the random bearing capacity of foundations in $3 \mathrm{D}$ is not only computationally challenging (as evidenced by few publications on the topic), but also very important. Rectangular footings in industrial structures (i.e. where heavy loads can occur and the risk of failure is worth assessing) is the most common foundation type. The bearing capacity of a rectangular footing is, of itself, a 3D problem. The 3D modelling of a strip foundation located in spatially variable soil is also justified. As shown in [35], the modelling of a strip foundation in 2D can lead to much higher values of bearing capacity coefficients of variation than would result from a full 3D analysis. Thus, a 2D analysis of a strip footing may be a too conservative approach, which is of great importance when evaluating the probability of foundation failure.

The present work, which is an extension of earlier studies, aims to analyze the random bearing capacity of embedded square and strip footings resting on a natural spatially variable cohesive-frictional soil. FLAC3D is used to solve both types of boundary value problem. The wellrecognized soil known as Taranto clay is chosen as a cohesive-frictional soil. Since no information about the horizontal scale of fluctuation for that soil can be found in the literature, a parametric study of that value is performed to address the square footing problem. Random fields are generated using the Fourier series method (FSM) and then transformed to match the distributions of cohesion and friction angle. The same methodology is used to analyze the influence of 3D modelling of strip footings on the probabilistic bearing capacity characteristics.

This study is structured as follows. The next section presents the basic assumptions regarding the probabilistic modelling method, adopted distributions and values of the modelled soil parameters. The numerical modelling is presented in the subsequent section followed by the presentation of the obtained probabilistic results. The work is summarized by a section discussing the conclusions of the study. 


\section{Basic assumptions}

\subsection{Random field modelling}

Modelling the spatial variability in soil properties by random fields seems to be a reasonable solution if a random bearing capacity is under consideration, and it is well described in the literature $[12,23,30,39]$. In the present study, two soil properties are modelled using a random field: the cohesion and the angle of internal friction. The random fields under consideration are assumed to be weakly stationary and ergodic [14]. For both of them, the same correlation structure has been assumed by applying the following correlation function (often called the Markov-type function):

$\rho\left(\tau_{x}, \tau_{y}, \tau_{z}\right)=\exp \left(\frac{-2\left|\tau_{x}\right|}{\theta_{x}}+\frac{-2\left|\tau_{y}\right|}{\theta_{y}}+\frac{-2\left|\tau_{z}\right|}{\theta_{z}}\right)$

where $\left(\tau_{x}, \tau_{y}, \tau_{\mathrm{z}}\right)=\left(x_{2}-x_{1}, y_{2}-y_{1}, z_{2}-z_{1}\right)$. Parameters $\theta_{x}, \theta_{y}$ and $\theta_{z}$ are scales of fluctuation (correlation radii) in the directions $x, y$ and $z$, respectively. In the following, the acronym SOF is used instead of the term "scale of fluctuation."

Function (1) is commonly used in soil properties modelling. Accepting the same correlation function (with identical values for the SOF) for both the friction angle and cohesion random fields suggests that the spatial correlation of properties in a soil is an effect of its geological history rather than a "specific character" of a given soil parameter. The problem of SOF estimation has been intensively explored in the literature $[5,6,21,31,33,38,40]$. Generally, methods are well established for the vertical SOF ("variability with depth"), but not satisfactorily developed for the horizontal SOF. For this reason, the effect of horizontal SOF on bearing capacity probabilistic characteristics in this study will be the subject of a parametric study. In earlier papers, evaluating bearing capacity $[12,15]$, a simplification of the correlation structures has been imposed by assuming that the SOF is identical in all directions. On the other hand, as indicated by Cherubini [10], the value of the horizontal scale of fluctuation is usually greater than the vertical one. It was demonstrated in papers [30, 39] that, for a given vertical SOF, using the same value of SOF in both the vertical and horizontal directions may lead to smaller values of bearing capacity coefficient of variation compared to cases where the horizontal SOF was significantly greater than the vertical one. For this reason, the present study assumes significantly different values of SOF in the vertical and horizontal directions.
The statistical sampling carried out in the present study utilizes the Monte Carlo technique. Therefore, the numerical simulation of a random field under consideration plays a vital role. Here, based on one of the pioneering studies by Fenton and Griffiths [12], random fields that model soil strength parameters are obtained by the appropriate transformation of normal random fields (i.e. random fields with normal finite-dimensional distributions). For example (as suggested in papers by Griffiths and Fenton [15] and Fenton and Griffiths [12]), if the cohesion is assumed to be a log-normal random field $Y(\mathbf{x})$ (where $\mathbf{x} \in \mathrm{D}$, where $D$ is a three-dimensional domain), the transformed field is obtained from a normal random field $X(\mathbf{x})$ by applying the following transformation:

$Y(\mathbf{x})=\exp (X(\mathbf{x}))$

At a specified point $\mathbf{x}$, the probability density function (p.d.f.) of $Y(\mathbf{x})$ takes the form

$f(t)=\left\{\begin{array}{ll}\frac{1}{t \sigma_{\ln Y} \sqrt{2 \pi}} \exp \left\{-\frac{1}{2}\left(\frac{\ln t-\mu_{\ln Y}}{\sigma_{\ln Y}}\right)^{2}\right\}, & t>0 \\ 0, & t \leq 0\end{array}\right\}$

where parameters $\mu_{\ln Y}$ and $\sigma_{\ln Y}$ are the mean value and the standard deviation of the underlying normal distribution $X(\mathbf{x})$, respectively. The mean value $\mu_{Y}$ and the standard deviation $\sigma_{Y}$ of the log-normal distribution $Y(\mathbf{x})$ are related to $\mu_{\ln Y}$ and $\sigma_{\ln Y}$ by

$E[Y]=\mu_{Y}=\exp \left(\mu_{\ln Y}+\frac{1}{2} \sigma_{\ln Y}^{2}\right)$

$\sigma_{Y}^{2}=\mu_{Y}^{2}\left(\exp \left(\sigma_{\ln Y}^{2}\right)-1\right)$

With regard to the modelling of the friction angle, due to the bounded range of this parameter, the probability distribution function should be a function of a bounded support, where the support of a function is defined by: $\operatorname{supp}(f)=\operatorname{cl}\{x: f(x) \neq 0\}$ (cl denotes the closure operation). In order to meet this requirement, Fenton and Griffiths $[12,14]$ suggested the following transformation:

$Y(\mathbf{x})=a+\frac{1}{2}(b-a)\left[1+\tanh \left(\frac{m+s X_{0}(\mathbf{x})}{2 \pi}\right)\right]$

where $X_{0}(\mathbf{x})$ is the standard normal random variable. The support of the p.d.f. of $Y(\mathbf{x})$ is the interval $[a, b]$, and $m$ and $s$ are the distribution's parameters. The p.d.f. of $Y(\mathbf{x})$ takes the form: 
$f(t)= \begin{cases}\frac{\sqrt{\pi}(b-a)}{\sqrt{2} \mathrm{~s}(t-a)(b-t)} \exp \left\{-\frac{1}{2 \mathrm{~s}^{2}}\left[\pi \ln \left(\frac{t-a}{b-t}\right)-m\right]^{2}\right\}, & t \in(a, b) \\ 0 & t \notin(a, b)\end{cases}$

If $m=0$, the distribution is symmetric with respect to the centre of the variability interval $[a, b]$. The parameter $s$ is associated with the standard deviation of $Y(\mathbf{x})$; however, there is no closed form relation between them. By means of the third-order Taylor's expansion, the following approximation can be obtained:

$\sigma_{Y}^{2} \approx \frac{1}{4}(b-a)^{2} \frac{s^{2}}{4 \pi^{2}+s^{2}}$

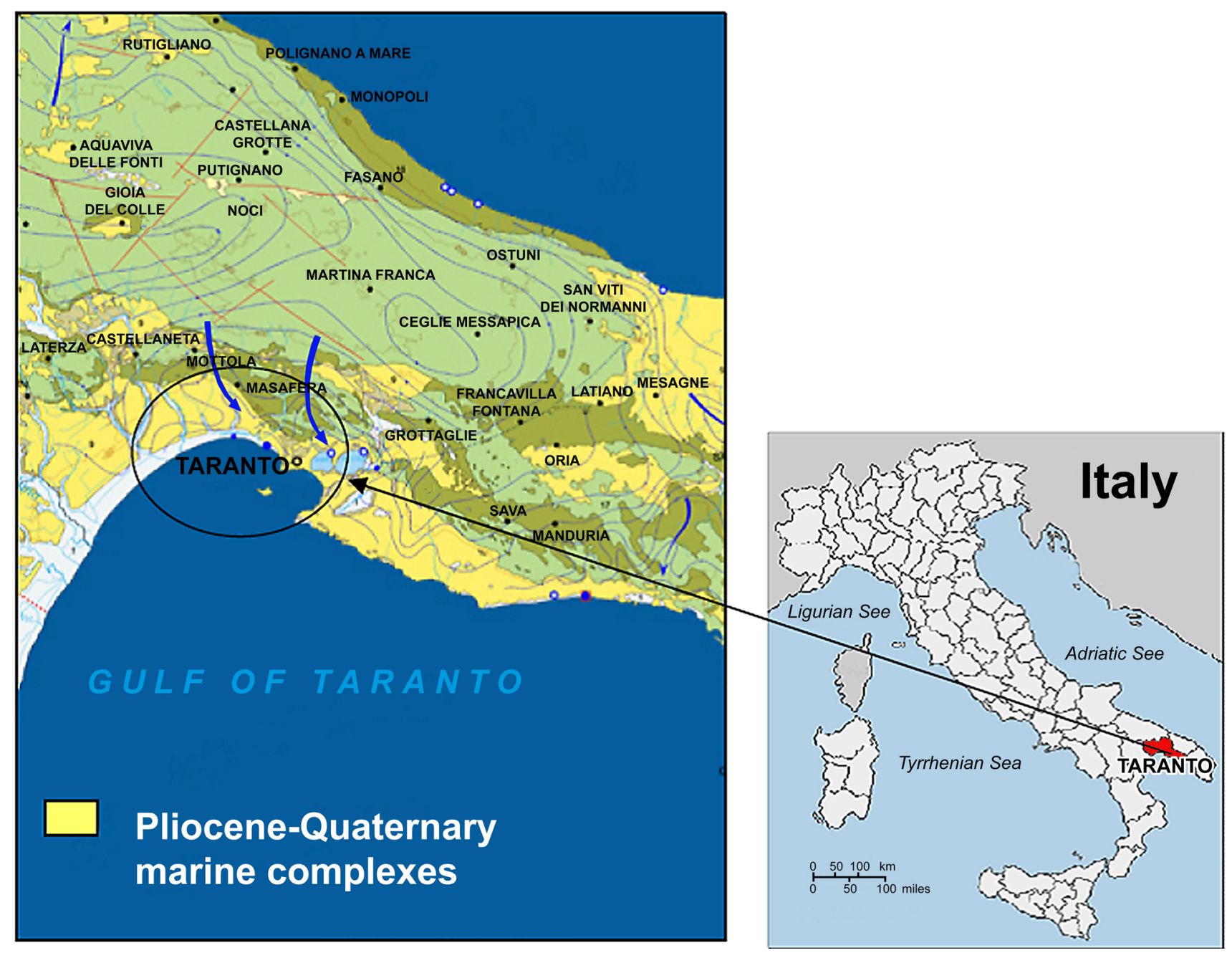

Fig. 1 Geographical location of Taranto clays 


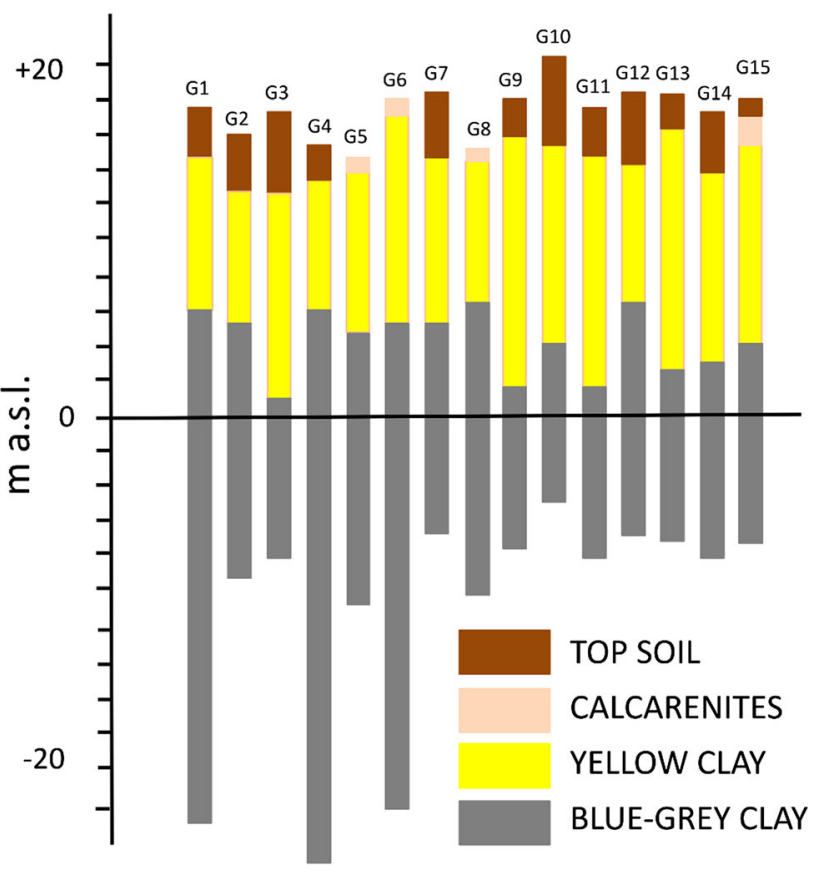

Fig. 2 Soil layers recognized by CPT tests

Table 1 Trends and vertical scales of the fluctuation from CPTs within upper and lower clay

\begin{tabular}{lll}
\hline Borehole & Trend equation $^{\mathrm{a}}(\mathrm{kPa})$ & Scale of fluctuation $\theta_{z}$
\end{tabular}
(m)

\begin{tabular}{|c|c|c|}
\hline \multicolumn{3}{|c|}{ Upper clay } \\
\hline G1 & $f(z)=54.671 z^{2}-21.21 z+5301$ & 0.195 \\
\hline G3 & $f(z)=12.44 z^{2}+113.06 z+2950$ & 0.401 \\
\hline G6 & $f(z)=40.713 z^{2}-439.7 z+5601$ & 0.207 \\
\hline G7 & $f(z)=73.690 z^{2}-172.2 z+9753$ & 0.401 \\
\hline G15 & $f(z)=11.027 z^{2}+212.3 z+2541$ & 0.436 \\
\hline \multicolumn{3}{|c|}{ Lower clay } \\
\hline G1 & $f(z)=149.11 z+4732$ & 0.536 \\
\hline G3 & $f(z)=319.58 z+1722$ & 0.287 \\
\hline G6 & $f(z)=201.29 z+3700$ & 0.720 \\
\hline G7 & $f(z)=201.14 z+4036$ & 0.269 \\
\hline G15 & $f(z)=203.34 z+3699$ & 0.185 \\
\hline
\end{tabular}

${ }^{a} z$ is the depth in $m$ with respect to the upper surface of the specific layer, and $f(z)$ is the trend function of $q_{\mathrm{c}}$

consolidated and are mainly composed of illite and kaolinite minerals.

The statistical data in the cited studies were collected by means of CPT testing in 15 boreholes. The testing demonstrated the presence of two clay layers: an upper layer composed of yellow clay and a lower layer composed of blue-grey clay (Fig. 2). Both clays can be classified as clayey silt to silty clay.

The variability in the strength parameters for the Taranto clays was determined by means of the statistical
Table 2 Random mechanical properties characterization of blue-grey clay

\begin{tabular}{|c|c|c|c|c|c|}
\hline Variable & $\begin{array}{l}\text { Probability } \\
\text { distribution }\end{array}$ & $\begin{array}{l}\text { Mean } \\
\mu\end{array}$ & \multicolumn{2}{|c|}{$\begin{array}{l}\text { Standard } \\
\text { deviation } \sigma\end{array}$} & $\begin{array}{l}\text { Scale of } \\
\text { fluctuation } \\
\text { (vertical) } \theta_{z} \\
\text { (m) }\end{array}$ \\
\hline$c$ & $\begin{array}{l}\text { Log- } \\
\text { normal }\end{array}$ & $36 \mathrm{kPa}$ & \multicolumn{2}{|l|}{$20 \mathrm{kPa}$} & 0.5 \\
\hline \multirow[t]{2}{*}{$\varphi$} & \multirow[t]{2}{*}{$\begin{array}{l}\text { Bounded } \\
{[\text { Eq. (7)] }}\end{array}$} & \multirow[t]{2}{*}{$20^{\circ}$} & $\begin{array}{l}\text { Min } \\
5^{\circ}\end{array}$ & $\begin{array}{l}\operatorname{Max} \\
35^{\circ}\end{array}$ & \multirow[t]{2}{*}{0.5} \\
\hline & & & $\begin{array}{l}\sigma_{X}=5 . \\
(s=2.2\end{array}$ & $m=0)$. & \\
\hline
\end{tabular}

treatment of the CPT results. Data from five boreholes (selected from the fifteen boreholes presented in Fig. 2) for both the yellow and the blue-grey clays were analyzed. In order to obtain the residuals, a low-order polynomial trend (no higher than a quadratic) was removed by regressing the cone resistance $\left(q_{\mathrm{c}}\right)$ values using the ordinary least squares method. Furthermore, the geostatistical boundaries of the two Taranto clays were investigated by means of the interclass correlation coefficient [40]. The results showed the presence of a lithological boundary at a depth of approximately $11 \mathrm{~m}$. The mean trend in $q_{\mathrm{c}}$ with depth $z$, given by the trend equation $f(z)$ as well as the vertical scales of fluctuation that were obtained, are presented in Table 1. Unfortunately, the horizontal fluctuation scale was not investigated.

The scale of fluctuation was evaluated after the removal of the mean trend line from the $q_{\mathrm{c}}$ readings. As regards strength parameters, two approaches are possible. The first one assumes evaluation of the strength parameters $(\varphi$ and c) based on $q_{\mathrm{c}}$ readings, followed by estimation of the mean values $\mu_{\varphi}$ and $\mu_{c}$ as well as standard deviations $\sigma_{\varphi}$ and $\sigma_{c}$. The values determined for $\mu_{\varphi}, \sigma_{\varphi}$ and $\mu_{c}, \sigma_{c}$ are used as the first two statistical moments of the random field of $\varphi$ and the random field of $c$, respectively. The above approach allows the weak stationarity of both random fields under consideration to be preserved. The second approach allows the use of trends (of mean value and standard deviation) of $\varphi$ and $c$, by adding them during the simulation of random fields. However, in such an approach, the fields of $\varphi$ and $c$ are no longer stationary. Moreover, as was demonstrated in [24], the friction angle displayed almost no trend despite the evident trend in $q_{\mathrm{c}}$. In the present study, the first approach was utilized.

As described in Sect. 2.1, suggested distributions for the cohesion and friction angle are log-normal [Eq. (3)] and bounded [Eq. (7)] distributions, respectively. Based on the collected data and by applying Eqs. (4), (5) and (8), the parameters of the above-mentioned distributions were identified. The parameters of the probability distributions 
of soil properties obtained from the Taranto blue-grey clay measurements that were utilized in the present study are presented in Table 2.

The same parameters as presented in Table 2 were applied in study [39] following the suggestion of Cherubini [11]. From the data given in Table 2, the relatively high value of coefficient of variation $(\mathrm{CoV})$ of about 0.55 is obtained for $c$. This could be a consequence of applying the first approach mentioned above. However, even higher values of the coefficient of variation in $c$ have been reported in some earlier papers, e.g. [25]. Also, some investigation of the clay deposits of Lower Silesia (the region where the authors of the present study live) shows high values of the COVs of $c$ as reported in the Ph.D. thesis of Thao [37]. Additionally, using the same values of parameters as in earlier work of the authors (e.g. [30]) allows the effects of 3D and 2D modelling to be compared for similar variability in soil parameters.

Due to extensive computational time, only one value of the vertical fluctuation scale, $\theta_{z}=0.5 \mathrm{~m}$, was selected as a representative value for further computations.

\section{Numerical model}

The 3D probabilistic analysis presented in this paper concerns the bearing capacity of square and strip footings. The numerical computations were performed in the FLAC3D environment. The elastic-perfectly plastic Mohr-Coulomb material (with non-associated flow rule) was employed as a soil model. The Young's modulus, Poisson's ratio, unit weight and dilation angle were given non-random values of $E=35 \mathrm{MPa}, v=0.35, \gamma=19 \mathrm{kN} / \mathrm{m}^{3}$ and $\psi=0^{\circ}$, respectively. Only the parameters for the strength criterion (namely cohesion $c$ and friction angle $\varphi$ ) were assumed to be random. These parameters were modelled using random fields to recreate the probabilistic characteristics of Taranto clays (i.e. mean values, standard deviations, distribution types and vertical SOF as presented in Table 2). The fields of $c$ and $\varphi$ were assumed to be stochastically independent.

As mentioned in Sect. 2.1, the exponential function (1) has been chosen to establish the correlation structure in random fields within this study. The function (1) is positively defined (a sufficient and necessary condition according to Bochner's theorem [34]), reflects separability of the fields under consideration, gives the possibility of distinct scales of fluctuation in three directions and is suggested by many researchers (e.g. [28]).

To generate random fields with the autocorrelation function of type (1) for a given mesh, the algorithm proposed by Jha and Ching [22] (FSM) based on the Fourier series expansion was employed. The Fourier series method (like most of the generation methods) generates normally distributed fields. Because of that, for the log-normal field of cohesion, the underlying normal distribution parameters were first found by solving Eqs. (4) and (5) for $\mu_{\ln Y}$ and $\sigma_{\ln Y}$. Then, the generation was carried out, and the transformation (2) then applied to all generated values. In the case of the internal friction angle field, the parameter $s=2.27$ [see Eq. (8)] was evaluated to obtain a measured
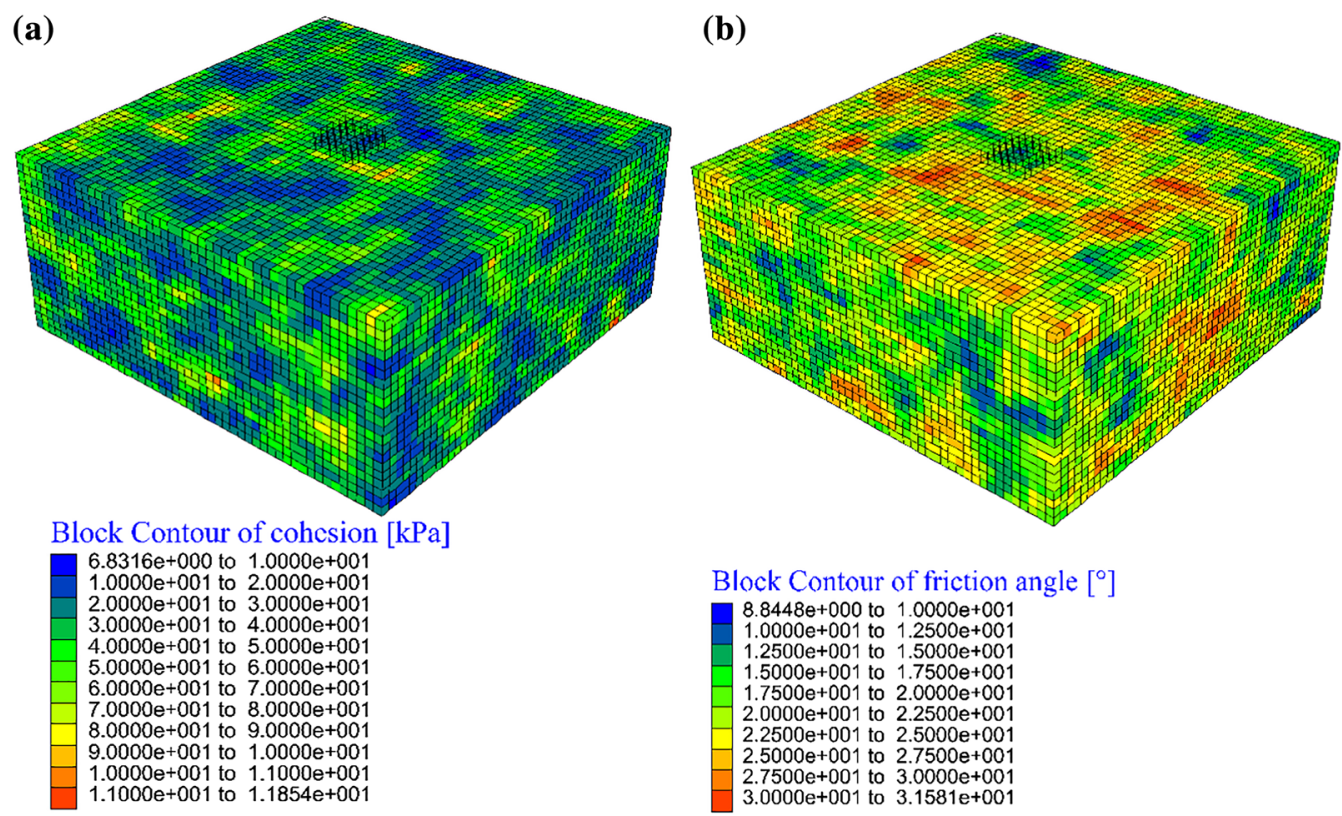

Block Contour of friction angle $\left[{ }^{\circ}\right]$

$8.8448 \mathrm{e}+000$ to $1.0000 \mathrm{e}+001$

$1.0000 \mathrm{e}+001$ to $1.2500 \mathrm{e}+001$

$2500 \mathrm{e}+001$ to $1.5000 \mathrm{e}+001$

$5000 \mathrm{e}+001$ to $1.7500 \mathrm{e}+001$

$.7500 \mathrm{e}+001$ to $2.0000 \mathrm{e}+001$

$2.0000 \mathrm{e}+001$ to $2.2500 \mathrm{e}+00$

$2500 \mathrm{e}+001$ to $2.5000 \mathrm{e}+001$

$2.5000 \mathrm{e}+001$ to $2.7500 \mathrm{e}+00$

$7500 \mathrm{e}+001$ to $3.0000 \mathrm{e}+001$

$3.0000 \mathrm{e}+001$ to $3.1581 \mathrm{e}+001$

Fig. 3 Contour diagrams of example realizations of random parameter fields generated using FSM for $8 \mathrm{~m} \times 8 \mathrm{~m} \times 3.5 \mathrm{~m}$ domain, $\theta_{x}=\theta_{y}=1 \mathrm{~m}$ and $\theta_{z}=0.5 \mathrm{~m}$ : a the field of cohesion (log-normal) and $\mathbf{b}$ the field of the friction angle [distribution with p.d.f. given by Eq. (7)] 
standard deviation for the given range of bounds. Next, the generated standard normal field was transformed using Eq. (6). For both problems analyzed (square footing and strip footing), the vertical SOF was assumed to be $0.5 \mathrm{~m}$. Since the value of the horizontal scale of fluctuation for Taranto clay was not investigated, some typical values of horizontal SOF have been assumed as specified in the next subsections. In all the present analyses, both horizontal SOFs (namely $\theta_{x}$ and $\theta_{y}$ ) were assumed to be equal. Example realizations of the log-normal field of cohesion and the field of friction angle [with p.d.f. defined by Eq. (7)] for the mesh applied to the square footing problem are presented in Fig. 3. Both the range of values for the typical realization as well as the size of strongly correlated clusters for the given SOFs are shown.

\subsection{Square footing problem}

For the square footing problem, the footing was assumed to be rigid, smooth and only vertically loaded. The horizontal dimensions of the footing were assumed to be $1.17 \times 1.17 \mathrm{~m}$. The boundary conditions were set as follows: The displacement of nodes lying on the external $x-$ $z$ and $y-z$ planes (where $z$ is the vertical direction) of the cuboid domain was fixed in directions normal to the planes and on the bottom $x-y$ plane in all three directions. The 1-m embedment was simulated using the additional loading of $19 \mathrm{kPa}$ applied to the upper surface of the domain everywhere except the foundation area. The footing was modelled as $7 \times 7$ nodes spaced $0.17 \mathrm{~m}$ (in both directions) with an applied constant velocity of displacement of the order $5 \times 10^{-5} \mathrm{~m} /$ time step. The bearing capacity was defined as the maximum vertical force which can be applied to the footing. Knowing this value, the value of the maximum (average) vertical stress under the footing can also be easily calculated (by dividing the force by the area of the footing). The force was calculated as the sum of vertical reactions in all the footing's nodes. This value stabilized after several thousand steps when it reached the limit value of the load bearing capacity.

The dimension of the domain (surrounding the footing) was found to be large enough to minimize the effects of the boundary on the obtained bearing capacity. To determine that dimension, a non-random study was first conducted. The $c$ and $\varphi$ values were assumed to be equal to their mean values, i.e. $36 \mathrm{kPa}$ and $20^{\circ}$, respectively. All other parameters were assumed to be the same as specified in the previous section. Due to the symmetry of the non-random problem, only one quadrant of the problem domain was considered. The obtained values for the footing bearing capacity $Q_{\mathrm{f}}$ for the dimensions of the domain's quadrant equalling 3,2 and $1 \mathrm{~m}$, together with respective images of the plastic zones, are presented in Fig. 4. The blue, brown and pink colours in the figure denote that the cell is in an elastic state (without plastic history), plastic state (yielding in shearing) or elastic state with plastic history, respectively. The nodes associated with the footing are marked with vertical black lines. As shown in Fig. 4, the boundary effect is limited. The case "a" in which the whole plastic zone is contained in the domain is treated as the reference case. It was verified that any enlargement in the domain dimension did not change the obtained value for the bearing capacity. Compared to situations in which the plastic zone only "touches" the domain's boundary (case "b"), no significant decrease in load bearing capacity was observed. Only when the area of contact between plastic zones and the boundary was very large (case "c"), there was a significant decrease in the bearing capacity observed.

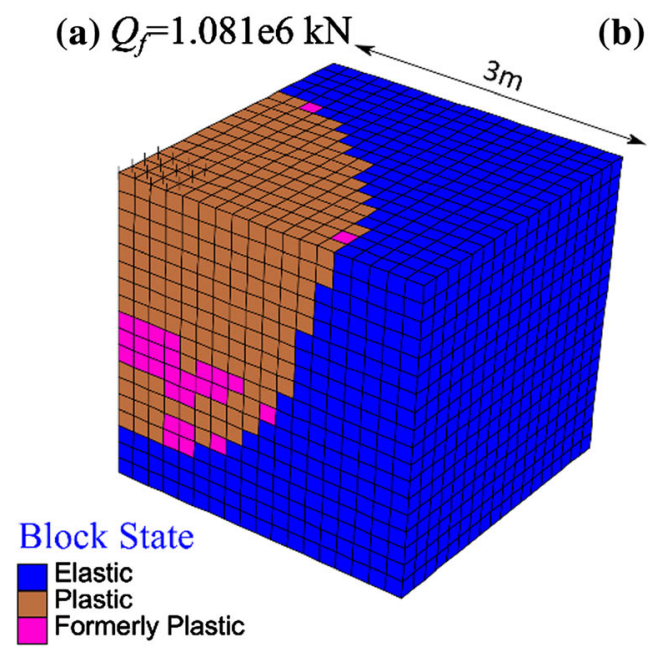

(b) $Q_{f}=1.081 \mathrm{e} 6 \mathrm{kN}$

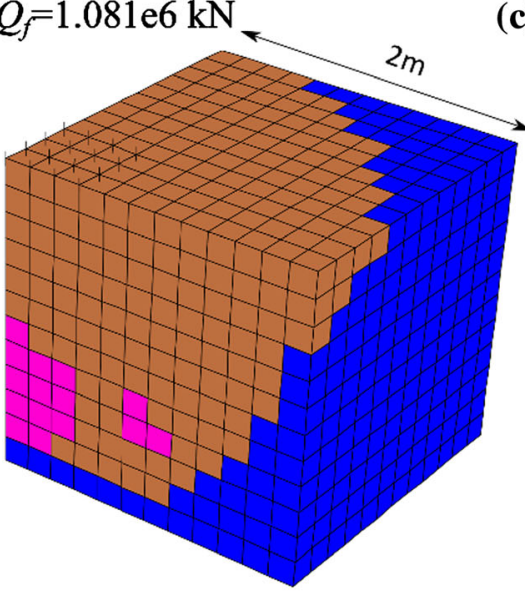

(c) $Q_{f}=9.999 \mathrm{e} 5 \mathrm{kN}$

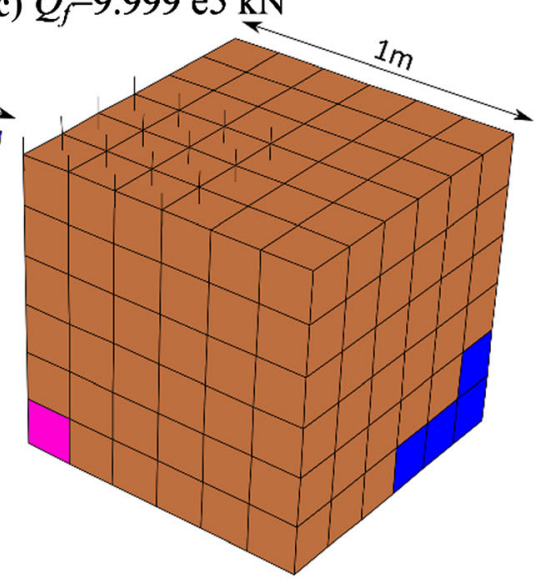

Fig. 4 Plastic zones under the square footing. The dimensions of the analyzed part (domain quadrant) was assumed to be a $3 \mathrm{~m}, \mathbf{b} 2 \mathrm{~m}$ or $\mathbf{c} 1 \mathrm{~m}$ 
(a)

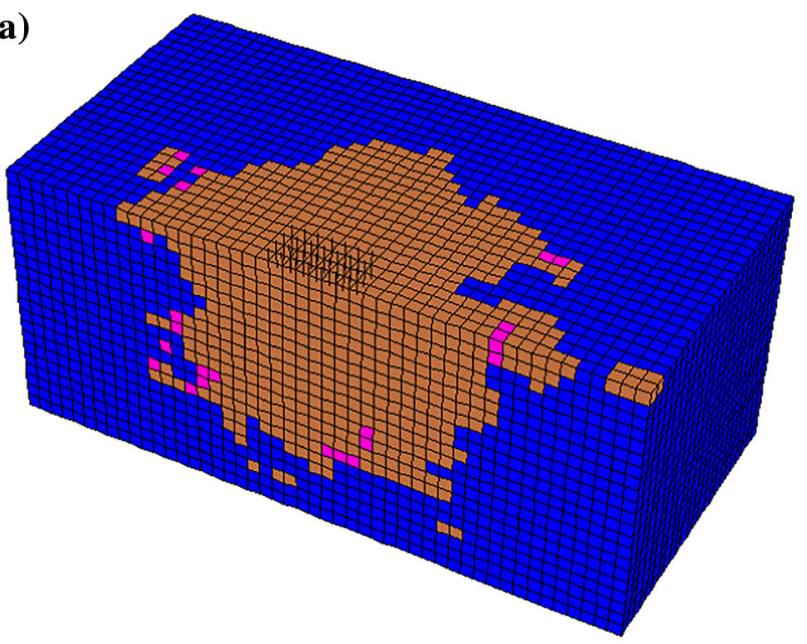

(b)

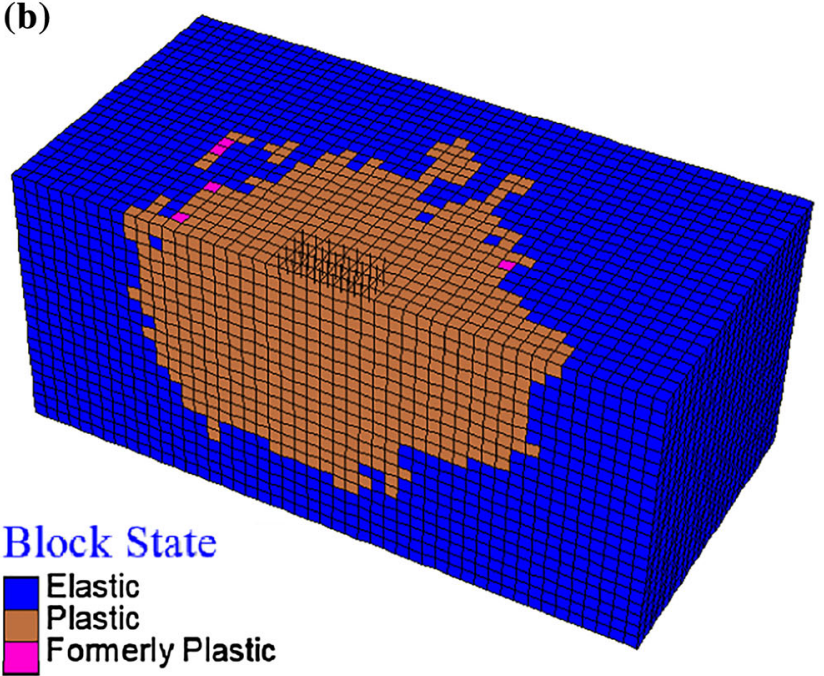

(c)

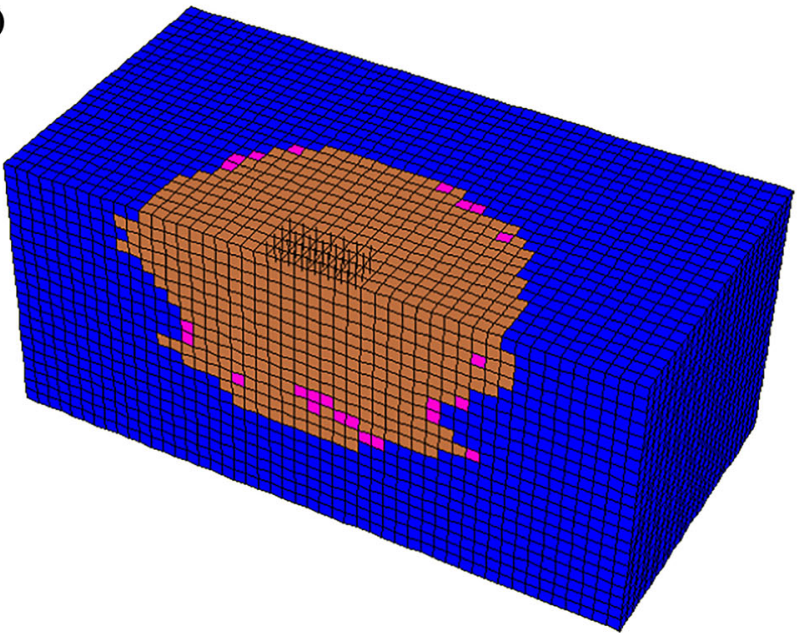

(d)

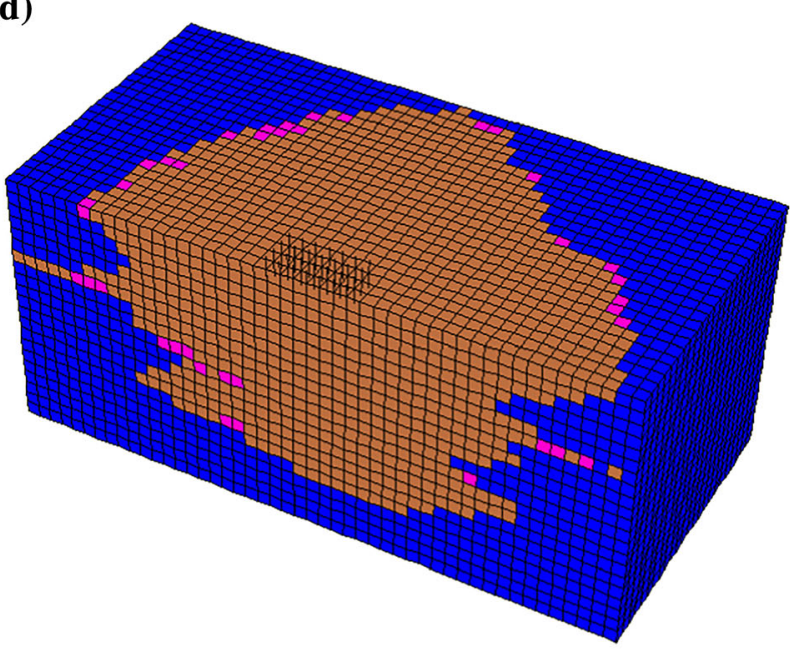

Fig. 5 Representative images of plastic zones for half of the considered domain: $\mathbf{a}, \mathbf{b}$ for $\theta_{\mathrm{x}}=\theta_{y}=1 \mathrm{~m}$; $\mathbf{c}, \mathbf{d}$ for $\theta_{\mathrm{x}}=\theta_{y}=30 \mathrm{~m}$

Thus, if all or almost all of the plastic zones were contained in the domain, the influence of the boundary was negligible.

A similar analysis was conducted for the problem with strength parameters modelled with random fields. Obviously, in that case, the problem was no longer symmetrical; the whole domain needed to be analyzed instead of just one quadrant. For a few assumed horizontal SOFs ranging from 1 to $30 \mathrm{~m}$, the influence of the domain size on the mean value of bearing capacity was tested. Since it seemed that the cases of larger SOF were more sensitive to the domain being too small, this influence was carefully investigated in the case of a horizontal SOF of $30 \mathrm{~m}$. Finally, the domain size of $8 \times 8 \times 3.5 \mathrm{~m}$ was found to be satisfactory, and enlarging the domain did not change the mean value by more than $0.5 \%$ (although that difference could be the effect of probabilistic modelling). With the assumed uniform grid with finite difference zone dimensions of $0.17 \times 0.17 \times 0.17 \mathrm{~m}$, a mesh of $48 \times 48 \times 21$ zones was obtained. In Fig. 5, some exemplary plastic zones obtained in different realizations for that domain are presented. The same colour coding as shown in Fig. 4 is used. Although the entire domain was analyzed, only half of it is shown in the figure. This is to show the plastic zones are not only on the boundary of the domain, but also directly under the footing. Two of the presented realizations were obtained for minimal $(1 \mathrm{~m})$ and the other two for maximal $(30 \mathrm{~m})$ considered horizontal SOFs. (The zones for $\mathrm{SOF}=30 \mathrm{~m}$ are easy to recognize as they are much more symmetrical.) As shown in Fig. 5, in each case, almost the whole plastic zone is contained inside the domain. However, it should be noted that for the horizontal SOF of $30 \mathrm{~m}$, realizations in which the plastic zone is "touching" the boundary are much more frequent. It was also found that for the cases of higher horizontal SOF, reducing the domain dimension resulted in numerical errors that, even though they were few in number, could significantly influence the mean value of the bearing capacity. 
For the given domain, the influence of the horizontal SOF value on the probabilistic characteristics of bearing capacity was investigated. Five different horizontal SOFs (i.e. 1, 2, 5, 10 and $30 \mathrm{~m}$ ) have been tested. For each case, 300 Monte Carlo simulations (MCS) have been computed. This number was limited due to the calculation time: obtaining 300 solutions took about 2 weeks of work using a single processor core on a modern PC.

\subsection{Strip footing problem}

The same procedure for modelling was also used to analyze the impact of the 3D field effect on the bearing capacity of the strip foundation. The $1.17 \mathrm{~m}$ wide perfectly smooth and rigid strip footing embedded $1 \mathrm{~m}$ into cohesive-frictional soil was considered. All the soil parameters as well as the field generation process and the procedure of finding the critical load were the same as described previously. This time, the bearing capacity was defined as the maximum allowable vertical force per metre of the foundation length. The horizontal dimension of the domain in the direction perpendicular to the strip footing and the vertical dimension were once again chosen to avoid boundary effects. Based on the analysis of the influence of the domain dimensions on the mean value of the bearing capacity, a width (perpendicular horizontal dimension) of $14 \mathrm{~m}$ and depth (vertical dimension) of $6 \mathrm{~m}$ were found to be satisfactory. For these domain dimensions, plastic zones quite often "touched" the boundary, but simulations carried out with increased dimensions hardly affected the results (apart from a significant extension of the calculation time). In fact, the obtained difference in mean value was of the order of $0.2 \%$. Because the uniform grid of cubic zones with all dimensions equal to $0.17 \mathrm{~m}$ was used (identically to the square footing problem), the number of zones in a single slice of the grid (in the plane perpendicular to the direction of the strip footing) was $84 \times 36$.

In the case of a strip footing, the impact of modelling the foundation in 3D (on a 3D spatially variable soil) on the footing load carrying capacity results was investigated. A parametric study of that case did not concern the horizontal SOF, but investigated the effect of the modelled length of the strip footing. Only one case of horizontal SOF was analyzed, namely $\theta_{x}=\theta_{y}=2 \mathrm{~m}$. The analysis included five series of calculations, each for different lengths of strip footing, i.e. $0.17,1,2,4$ and $6 \mathrm{~m}$ ( 1 zone, 6 zones, 12 zones, 24 zones and 36 zones, respectively). The first series $(0.17 \mathrm{~m})$ was considered to be a $2 \mathrm{D}$ problem, but in the entire series, there was a general assumption that only part of the foundation was being modelled because the foundation runs through the entire modelled length of the domain, and neither of its ends were modelled (see Fig. 6).
Similarly, as in the case of the square footing, each series consisted of $300 \mathrm{MCS}$. In this case, the analysis was even more time consuming. In particular, 300 MCSs of a 6-m-long portion of the strip footing required about 6 weeks of computational work for a single core. Representative plastic zones (using the same colour coding as previously) obtained for four different modelled lengths of footing are presented in Fig. 6. (The results of the fifth series, which are not presented here, were qualitatively similar to series 4.) The results obtained for the bearing capacity of both the square and strip footings are presented in the next section.

\section{Results and discussion of the probabilistic analysis}

\subsection{Bearing capacity of square footing}

As mentioned in the previous section, the numerical simulation for the square footing problem was conducted to determine the influence of the horizontal SOF on the probabilistic results. For each considered SOF, $N=300$ realizations of MCS were carried out. Based on the collected data, in each case, both the mean and coefficient of variation $(\mathrm{CoV})$ of $Q_{\mathrm{f}}$ were estimated. The diagrams showing the influence of these two characteristics as a function of the horizontal SOF are presented in Fig. 7. For comparative purposes also, the mean value of $Q_{\mathrm{f}}$ obtained for the non-random case (where the values of $c$ and $\varphi$ were assumed to be their mean values, i.e. $36 \mathrm{kPa}$ and $20^{\circ}$, respectively) is presented in Fig. 7a. As shown in the figure, for increasing values of the horizontal SOF, both the mean value and the $\mathrm{CoV}$ of bearing capacity increase, but these soon stabilize for higher values of SOF. Slight deviations from the observed trend obtained in both diagrams for horizontal SOF between 10 and $30 \mathrm{~m}$ may have resulted from the limited number of realizations. Since all mean values obtained lie in a very small range (about 2-3\% difference between all obtained values), the observed increase in the mean is very small. On the other hand, the change in $\mathrm{CoV}$ is quite significant. Its value increases from 0.15 (obtained for the horizontal scale of $1 \mathrm{~m}$ ) to 0.36 (obtained for the horizontal scales of $10 \mathrm{~m}$ or $30 \mathrm{~m}$ ). It is worth noting that the maximum value of $\mathrm{CoV}$ obtained for high values of SOF as well as the general trend in the $\mathrm{CoV}$ function is in good agreement with the results obtained in the previous study of a strip foundation modelled in 2D on the same soil for high values of horizontal SOF [30].

The probability distributions of the bearing capacity for the individual series of calculations were estimated and tested using Kolmogorov's goodness-of-fit test. For the hypothetical log-normal distribution of bearing capacity, 
(a)

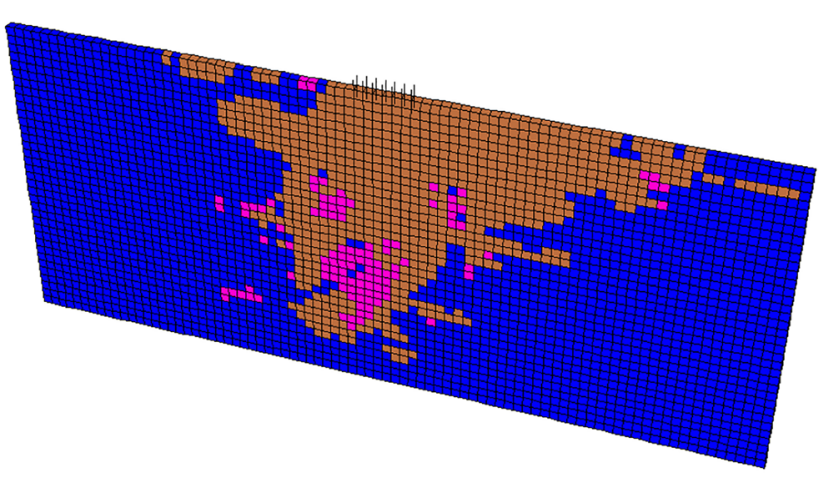

(b)

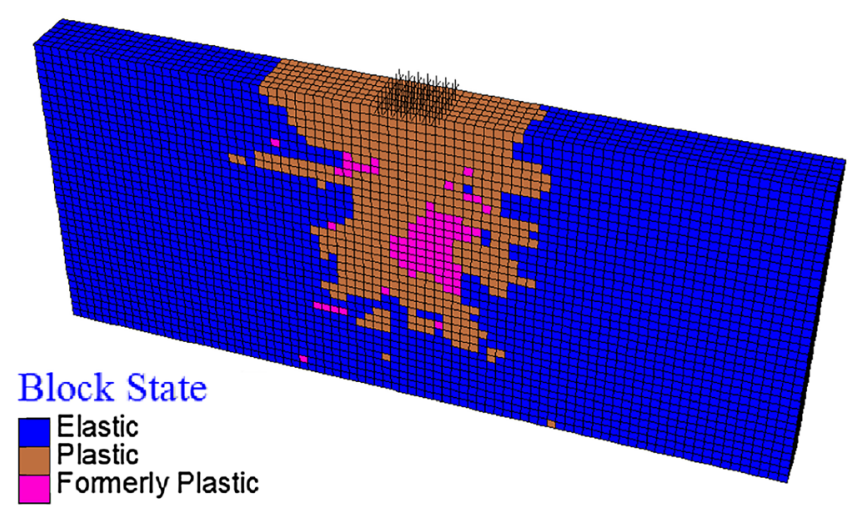

(c)

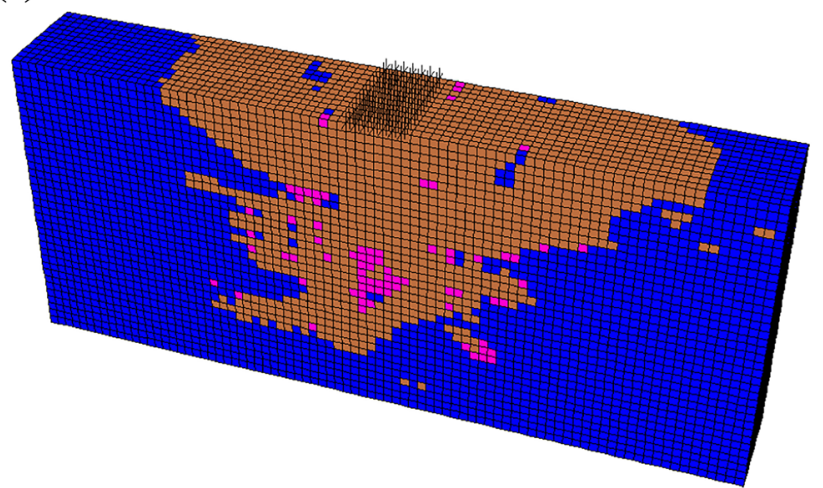

(d)

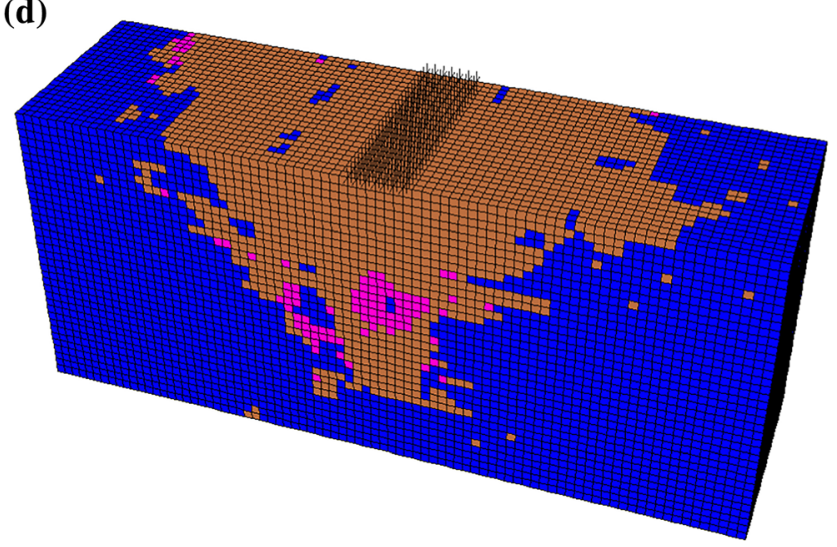

Fig. 6 Representative plastic zones obtained for four different lengths of modelled strip footing $(0.17 \mathrm{~m}, 1 \mathrm{~m}, 2 \mathrm{~m}$ and $4 \mathrm{~m})$. The footing nodes are denoted with vertical black lines
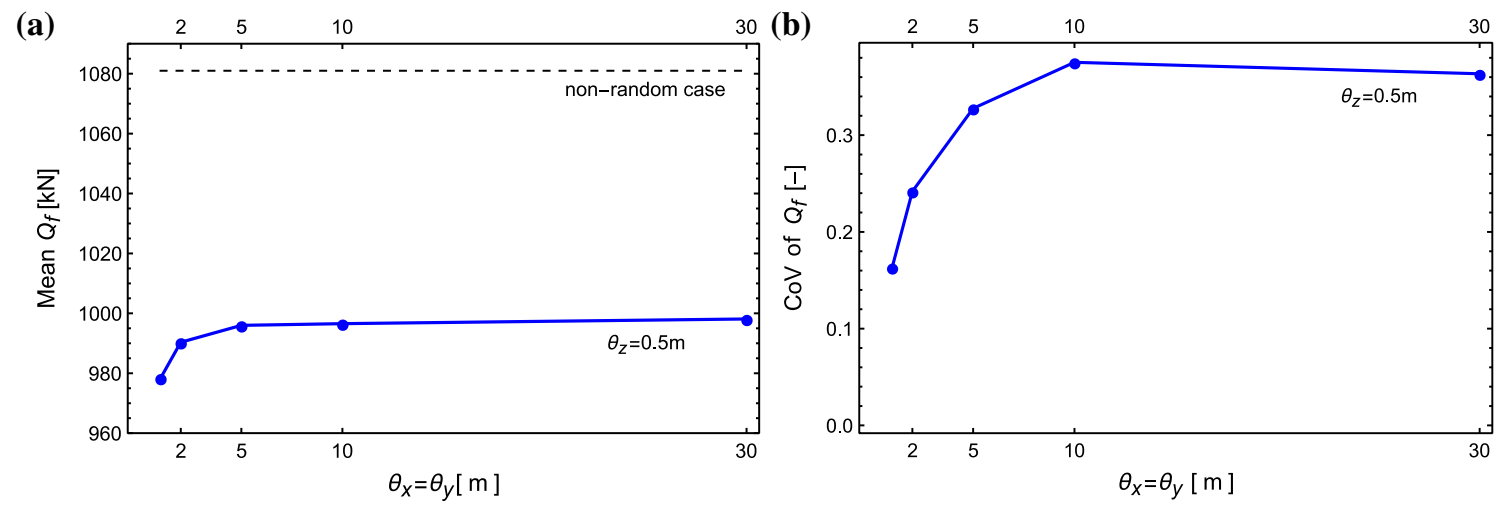

Fig. 7 Influence of the horizontal fluctuation scale on a mean value and $\mathbf{b} \mathrm{CoV}$ of square footing bearing capacity

the test results were in the range of $30-80 \%$. The obtained estimated distributions for different values of the horizontal scale of fluctuation are presented in Fig. 8.

Since the sample size was quite limited $(N=300)$, the estimated distributions presented in Fig. 8 should be treated as only a rough approximation, especially in cases when the tails of the distributions have not been precisely estimated. Nevertheless, a simple reliability analysis was performed by assuming that the obtained distributions were the correct ones.

Let us define the probability of failure as the probability that the bearing capacity $Q_{\mathrm{f}}$ is lower than a certain allowable (minimal) value $Q_{\mathrm{d}}$, namely

$p_{\mathrm{f}}=p\left(Q_{\mathrm{f}} \leq Q_{\mathrm{d}}\right)=\Phi(-\beta)$,

where $\Phi$ is the cumulative distribution function of the onedimensional standard normal distribution and $\beta$ is the 


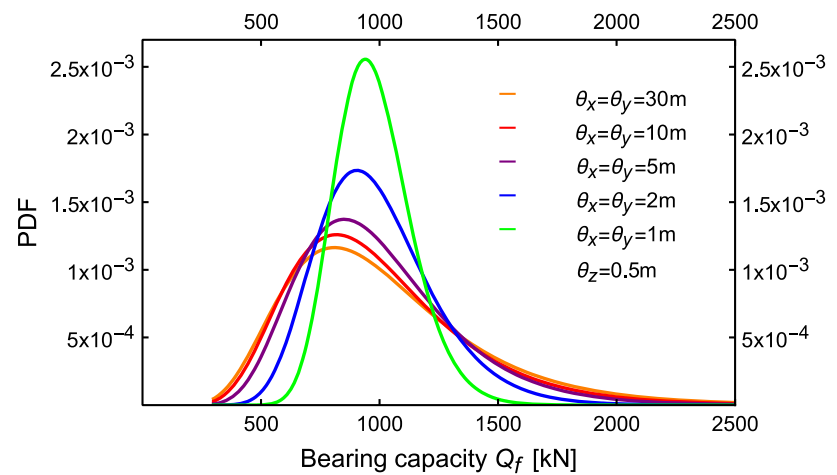

Fig. 8 Estimated distributions of the bearing capacity $Q_{\mathrm{f}}$ for different values of horizontal SOF

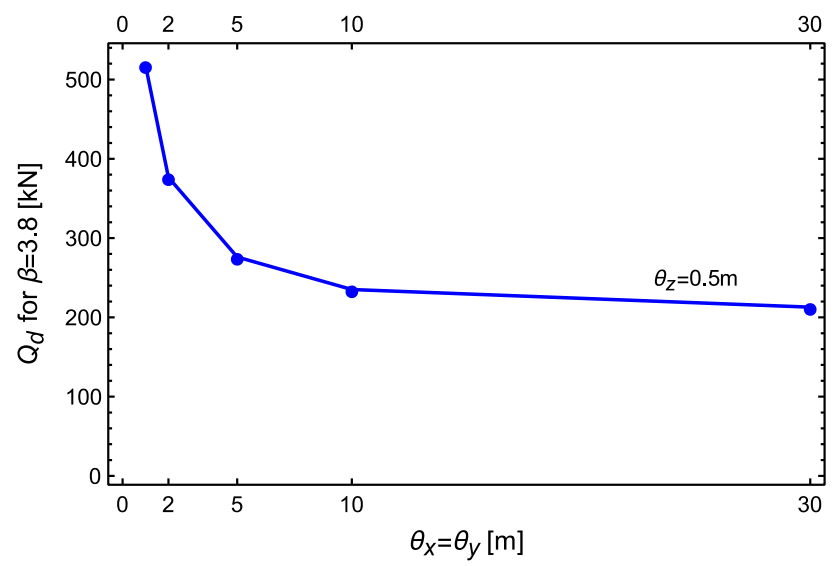

Fig. 9 Allowable value $Q_{\mathrm{d}}$ of square footing bearing capacity corresponding to $\beta=3.8$ versus the horizontal SOF

reliability index. According to the Eurocode regulations, the target reliability index for the ultimate limit states of RC2 reliability class structure (ordinary buildings and their foundations) having a design working life of 50 years has been specified as 3.8. Using this value, the values of $Q_{\mathrm{d}}$ as a function of horizontal SOF were calculated.
The obtained results are presented in Fig. 9. As shown, in the case of small values of SOF, the allowable value of $Q_{\mathrm{d}}$ is significantly higher. In contrast, for higher values of SOF, which seem to be the situation for the natural soil [10], the value is much lower but quite stable. Figure 9 corresponds well to Fig. 7. Both the mean value and standard deviation are almost constant (see Fig. 7) for SOF greater than 10 , resulting in an almost constant probability of exceeding the allowable value $Q_{\mathrm{d}}$.

\subsection{Bearing capacity of strip footing}

The analysis of the bearing capacity of the strip footing aimed to determine the impact of $3 \mathrm{D}$ modelling of the footing and soil on the obtained probabilistic results. As previously mentioned, the parametric study concerned the modelled length of the foundation. Only one horizontal SOF value (i.e. $\theta_{x}=\theta_{y}=2 \mathrm{~m}$ ) was assumed. For each of the foundation lengths considered, $N=300$ MCSs were performed.

The estimated means and CoVs are presented in Fig. 10. As previously mentioned, for comparative purposes the value of $Q_{\mathrm{f}}$ obtained for the non-random case (where the values of $c$ and $\varphi$ were assumed to be their mean values, i.e. $36 \mathrm{kPa}$ and $20^{\circ}$, respectively) is also presented in the figure. The minimum length of the modelled foundation equals $0.17 \mathrm{~m}$, corresponding to a single slice of the finite difference mesh as indicated in the previous section. The increase in the mean value of the bearing capacity, which occurred for higher values of the modelled length of the strip foundation, was not significant; the maximum increment of the mean value was $6 \%$. In contrast, the $\mathrm{CoV}$ of the bearing capacity significantly decreased for higher values of the model length. The changes in both the mean and the $\mathrm{CoV}$ of bearing capacity caused by the increase in the model length were the effect of averaging the bearing capacity along the foundation.
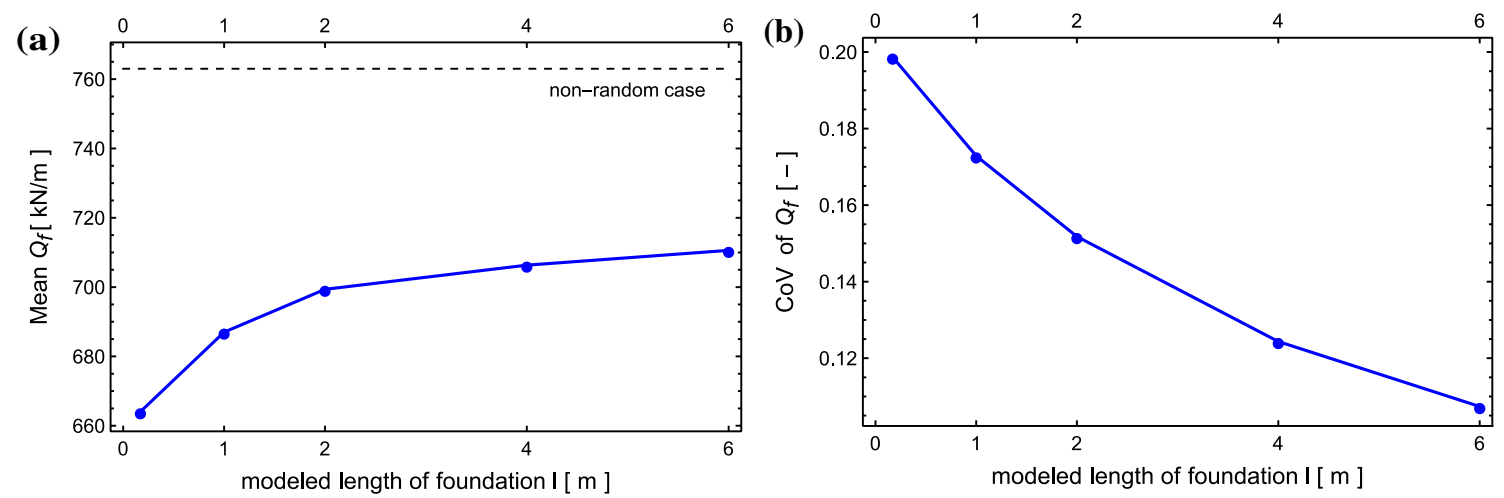

Fig. 10 Influence of the modelled length of the foundation on the probability characteristics of its bearing capacity $Q_{\mathrm{f}}$ : a mean value and $\mathbf{b}$ CoV for horizontal SOF of $2 \mathrm{~m}$ and vertical SOF of $0.5 \mathrm{~m}$ 


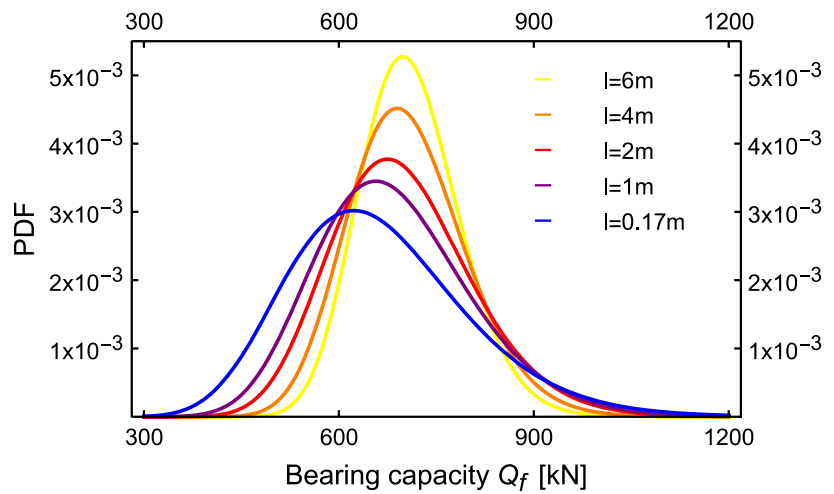

Fig. 11 Hypothetical distributions of bearing capacity obtained for different lengths of strip foundation

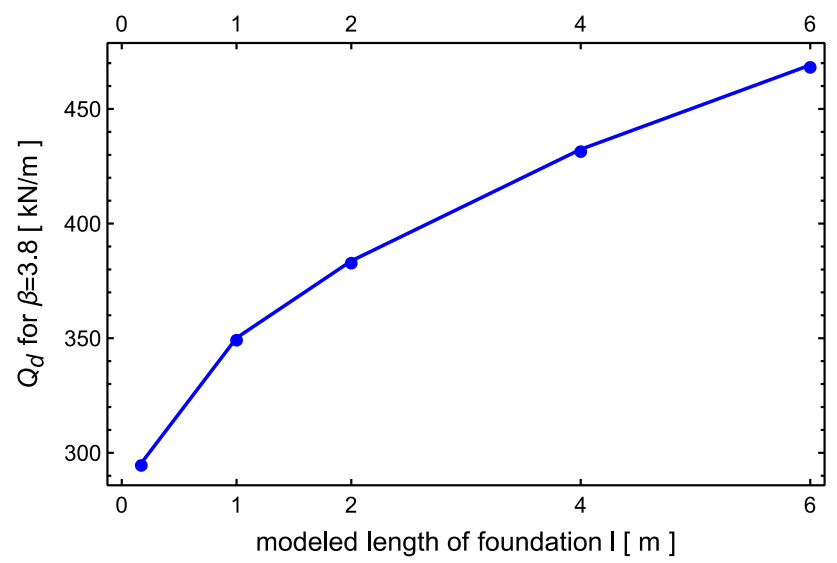

Fig. 12 Allowable values $Q_{\mathrm{d}}$ of strip footing bearing capacity corresponding to $\beta=3.8$ versus the modelled length of footing $l$

Since the range of values of mean bearing capacity is limited and the graph becomes flat for larger modelled lengths of the foundation, it seems that the value obtained for the length of $6 \mathrm{~m}$ is close to an "asymptotic" value. On the other hand, the diagram of the $\mathrm{CoV}$ is much steeper which indicates that for very long lengths of the foundation, the $\mathrm{CoV}$ of the bearing capacity can approach a much smaller value than the 0.1 obtained for $6 \mathrm{~m}$. These results seem to agree with the previously mentioned averaging effect. It should be noted that these results were obtained for a horizontal SOF equal to $2 \mathrm{~m}$, which is a relatively low value. Up until now (due to high computation costs), we have no results for higher values of the horizontal SOF in the case of the strip foundation. However, one can expect that for the horizontal SOF equal to infinity, there should be no influence of the modelled length of the foundation on the results.

Once again, in spite of the limited sample size, the probability distributions of the bearing capacity of the strip foundation were estimated and tested using the goodnessof-fit test. The results obtained for the Kolmogorov test were between 30 and $70 \%$, and the hypotheses of lognormal distributions were not rejected. The hypothetical distributions for differently assumed lengths of the model are presented in Fig. 11.

Once again, a simple reliability assessment was carried out. The allowable values of the bearing capacity $Q_{\mathrm{d}}$ corresponding to the value of the reliability index $\beta=3.8$ were evaluated. The results are presented in Fig. 12.

As shown in Fig. 12, the allowable value $Q_{\mathrm{d}}$ increases with the longer modelled length of a foundation. The change is significant: The allowable value $Q_{\mathrm{d}}$ for the modelled length of $6 \mathrm{~m}$ at $470 \mathrm{kN} / \mathrm{m}$ is more than 1.5 times greater than the $Q_{\mathrm{d}}$ of $270 \mathrm{kN} / \mathrm{m}$ obtained for $0.17 \mathrm{~m}$. It should be noted that the case of the minimum model length (equal to the length of the single zone) corresponds to the 2D random analysis of the strip foundation. The obtained results indicate that the $2 \mathrm{D}$ reliability analysis can be significantly conservative in comparison with $3 \mathrm{D}$ analysis. It seems that modelling such structures in 3D is necessary for the precise assessment of the probability of the foundation failure.

\section{Conclusions}

This paper presents a 3D analysis of the bearing capacity of square and strip footings on a cohesive-frictional soil. The cohesion and friction angle were modelled using random fields based on the study of the natural soil deposit, Taranto clay. The parameters for the probability distributions and the value of the vertical SOF were adapted from existing studies. Due to the lack of information in the literature regarding the horizontal SOF, a parametric study of that value was performed for the square footing problem. For the strip footing problem, the influence of 3D modelling on the bearing capacity was analyzed and the parameter study concerned the effect of the modelled length of the foundation on the boundary value problem.

The following conclusions can be drawn from this research:

(1) The issue of the random bearing capacity of a square or rectangular footing from the point of view of the reliability analysis constitutes a very important problem, as these kinds of foundations are very common in engineering practice. The problem requires 3D probabilistic modelling. Until recently, such a task has been beyond the computational capabilities of personal computers, and the analysis presented in this study indicates that this situation is changing.

(2) It was shown that the modelling of a random substrate with spatially variable properties requires 
much more attention than in a non-random case. Apart from the obvious inability to simplify the task due to a lack of symmetry (in random modelling, the latter does not occur), the size of the domain must also be properly selected in order to avoid boundary effects for all considered realizations of random fields.

(3) As shown for the square footing problem, the mean value for the bearing capacity increases with increasing values of horizontal SOF, but the changes are contained in a small range, and the value stabilizes at higher values of SOF.

(4) The $\mathrm{CoV}$ of the square footing bearing capacity increases significantly with an increase in the horizontal SOF, but it also stabilizes for large SOF values. The results for the $\mathrm{CoV}$ are comparable to those obtained in a 2D analysis of the same soil (see Pieczyńska-Kozłowska et al. [30], Fig. 8).

(5) Interesting conclusions also result from the $3 \mathrm{D}$ analysis of the strip foundation. The results clearly show that analyzing the strip footings in $2 \mathrm{D}$ overestimates the $\mathrm{CoV}$ of the bearing capacity, and it is probably a very conservative approach. Moreover, 3D modelling of the strip footing seems to be necessary for the precise assessment of the probability of the foundation failure.

(6) In this analysis, almost all the features of the actual foundation were modelled. The considered footing was an embedded one, placed on a self-weighted, natural cohesive-frictional soil. The only phenomena not modelled were eccentric and horizontal loads. It seems that their introduction into the model, although associated with certain complications (i.e. modelling of additional interfaces), is not a significant problem.

The presented analysis is not without limitations. First of all, due to the relatively high computational cost, the number of simulations in each series of calculations was limited to $N=300$. Although the results display some trends, this number is too small to properly estimate the probabilities of a foundation failure at their typical small values. The work associated with the modelling of the strip foundation also requires continuation (e.g. variation in the horizontal scale of fluctuation). The rapid development of computer processors as well as techniques accelerating reliability calculations provides hope that more accurate probabilistic modelling made in reasonable computation time will soon be possible.

Acknowledgements The authors would like to offer their special thanks to Professor Jianye Ching for sharing the 3D FSM code written in MATLAB and consulting on questions related to its usage.
Open Access This article is distributed under the terms of the Creative Commons Attribution 4.0 International License (http://creative commons.org/licenses/by/4.0/), which permits unrestricted use, distribution, and reproduction in any medium, provided you give appropriate credit to the original author(s) and the source, provide a link to the Creative Commons license, and indicate if changes were made.

\section{References}

1. Ahmed A, Soubra AH (2012) Probabilistic analysis of strip footings resting on a spatially random soil using subset simulation approach. Georisk Assess Manag Risk Eng Syst GeoHazards 6:188-201

2. Al-Bittar T (2012) Probabilistic analysis of shallow foundations resting on spatially varying soils. Doctoral dissertation, Nantes

3. Al-Bittar T, Soubra AH (2014) Combined use of the sparse polynomial chaos expansion and the global sensitivity analysis for the probabilistic analysis of the methodology for the shallow foundations resting on 3D random soil. In: Deodatis G, Ellingwood BR, Frangopol DM (eds) Safety, reliability, risk and lifecycle performance of structures and infrastructures. CRC Press, Boca Raton, pp 3261-3268

4. Ali A, Lyamin AV, Huang J, Sloan SW, Cassidy MJ (2016) Effect of spatial correlation length on the bearing capacity of an eccentrically loaded strip footing. In: 6th Asian-Pacific symposium on structural reliability and its applications, Shanghai, China

5. Bagińska I, Kawa M, Janecki W (2016) Estimation of spatial variability of lignite mine dumping ground soil properties using CPTu results. Studia Geotechnica et Mechanica 38(1):3-13

6. Bagińska I, Kawa M, Janecki W (2018). Estimation of spatial variability properties of mine waste dump using CPTu resultscase study. In: Cone penetration testing 2018. CRC Press, pp 109-115

7. Cafaro F, Cherubini C, Cotecchia F (2000) Use of the scale of fluctuation to describe the geotechnical variability of an Italian clay. In: Melchers, Stewart (eds), Proceeding of the 8th international conference on applications of statistics and probability in civil engineering (ICASP). Balkema, Rotterdam, pp 481-486

8. Cafaro F, Cherubini C (2002) Large sample spacing in evaluation of vertical strength variability of clayey soil. J Geotech Geoenviron Eng 128:558-568

9. Cassidy MJ, Uzielli M, Tian Y (2013) Probabilistic combined loading failure envelopes of a strip footing on spatially variable soil. Comput Geotech 49:191-205

10. Cherubini C (1997) Data and considerations on the variability of geotechnical properties of soils. In: Proceedings of the international conference on safety and reliability, ESREL, vol 97, pp $1583-1591$

11. Cherubini C (2009) On the statistical data of the Taranto clays. Private communication

12. Fenton GA, Griffiths DV (2003) Bearing capacity prediction of spatially random $c-\varphi$ soils. Can Geotech J 40(1):54-65

13. Fenton GA, Griffiths DV (2005) Three-dimensional probabilistic foundation settlement. J Geotech Geoenviron Eng 131(2):232-239

14. Fenton GA, Griffiths VD (2008) Risk assessment in geotechnical engineering. Wiley, New York

15. Griffiths DV, Fenton GA (2001) Bearing capacity of spatially random soil: the undrained clay Prandtl problem revisited. Géotechnique 54(4):351-359 
16. Griffiths DV, Fenton GA, Manoharan N (2002) Bearing capacity of rough rigid strip footing on cohesive soil: probabilistic study. J Geotech Geoenviron Eng 128(9):743-755

17. Hicks MA, Spencer WA (2010) Influence of heterogeneity on the reliability and failure of a long 3D slope. Comput Geotech 37(7-8):948-955

18. Hicks MA, Nuttall JD, Chen J (2014) Influence of heterogeneity on 3D slope reliability and failure consequence. Comput Geotech 61:198-208

19. Hicks MA, Li Y (2018) Influence of length effect on embankment slope reliability in 3D. Int J Numer Anal Methods Geomech 42(7):891-915

20. Huang J, Lyamin AV, Griffiths DV, Sloan SW, Krabbenhoft K, Fenton GA (2013) Undrained bearing capacity of spatially random clays by finite elements and limit analysis. In: 18th international conference on soil mechanics and geotechnical engineering

21. Jaksa MB, Kaggwa WS, Brooker PI (1999) Experimental evaluation of the scale of fluctuation of a stiff clay. In: Proceedings of the 8th international conference on application of statistics and probability, AA Balkema, Rotterdam, pp 415-422

22. Jha SK, Ching J (2013) Simplified reliability method for spatially variable undrained engineered slopes. Soils Found 53(5):708-719

23. Kawa M, Puła W, Suska M (2016) Random analysis of bearing capacity of square footing using the LAS procedure. Stud Geotech Mech 38(3):3-13

24. Kawa M, Bagińska I, Wyjadłowski M (2019) Reliability analysis of sheet pile wall in spatially variable soil including CPTu test results. Arch Civ Mech Eng 19(2):598-613

25. Kulhawy FH, Roth MJS, Grigoriu MD (1991) Some statistical evaluations of geotechnical properties. In: Proceedings of ICASP6, international conference on application of statistics and probability in civil engineering

26. Li YJ, Hicks MA, Vardon PJ (2016) Uncertainty reduction and sampling efficiency in slope designs using 3D conditional random fields. Comput Geotech 79:159-172

27. Li Y, Hicks MA, Vardon PJ (2017) Cost-effective design of long spatially variable soil slopes using conditional simulation. In: Geo-Risk 2017, pp 394-402

28. Phoon KK, Quek ST, An P (2003) Identification of statistically homogeneous soil layers using modified Bartlett statistics. J Geotech Geoenviron Eng 129(7):649-659

29. Pieczyńska J, Puła W, Griffiths DV, Fenton GA (2011). Probabilistic characteristics of strip footing bearing capacity evaluated by random finite element method. In: Proceedings of the 11th international conference on applications of statistics and probability in soil and structural engineering (ICASP), Zurich

30. Pieczyńska-Kozłowska JM, Puła W, Griffiths DV, Fenton GA (2015) Influence of embedment, self-weight and anisotropy on bearing capacity reliability using the random finite element method. Comput Geotech 67:229-238

31. Pieczyńska-Kozłowska JM, Puła W, Vessia G (2017) A collection of fluctuation scale values and autocorrelation functions of fine deposits in Emilia Romagna Palin, Italy. Geo-Risk 2017. American Society of Civil Engineers, Reston, cop. 2017, pp 290-299

32. Popescu R, Deodatis G, Nobahar A (2005) Effects of random heterogeneity of soil properties on bearing capacity. Probab Eng Mech 20(4):324-341

33. Puła W, Bagińska I, Kawa M, Pieczyńska-Kozłowska J (2017) Estimation of spatial variability of soil properties using CPTU results: a case study. In: 6th Młynarek Z, Wierzbicki J (eds) Insitu and laboratory characterization of OC subsoil. Exemplum, Poznań, pp 23-32

34. Reed M, Simon B (1975) Methods of modern mathematical physics. Fourier analysis, self-adjointness, vol II. Academic Press, London

35. Simoes JT, Neves LC, Antao AN, Guerra NM (2014) Probabilistic analysis of bearing capacity of shallow foundations using three-dimensional limit analyses. Int $\mathrm{J}$ Comput Methods 11(02): 1342008

36. Suchomel R, Mašín D (2011) Probabilistic analyses of a strip footing on horizontally stratified sandy deposit using advanced constitutive model. Comput Geotech 38(3):363-374

37. Thao NTP (1984) Parametry statystyczne parametrów geotechnicznych wybranych warstw geologicznych podłoża gruntowego określonego rejonu m. Wrocławia, Prace Naukowe Instytutu Geotechniki Politechniki Wrocławskiej, 14 (in Polish with English abstract)

38. Vanmarcke EH (1977) Probabilistic modeling of soil profiles. J Geotech Eng Div ASCE 103(GT11):1227-1246

39. Vessia G, Cherubini C, Pieczyńska J, Puła W (2009) Application of random finite element method to bearing capacity design of strip footing. J GeoEng 4(3):103-112

40. Wickremesinghe D, Campanella RG (1991) Statistical methods for soil layer boundary location using the cone penetration test. In: Proceedings of ICASP6, Mexico City, vol 2, pp 636-643

Publisher's Note Springer Nature remains neutral with regard to jurisdictional claims in published maps and institutional affiliations. 